\title{
Impact of climatic variability on growth performance of Fogera cattle in Northwestern Ethiopia
}

\author{
Michael Abera $^{\text {ab* }} \mid$ Mitiku Eshetu $\mid$ Yesihak Yusuf Mummed'| Fabio Pilla $\mid$ Zewdu Wondifraw \\ ${ }^{a}$ Africa Center of Excellence for Climate Smart Agriculture and Biodiversity Conservation, Haramaya University, Haramaya, Ethio pia. \\ bepartment of Animal Sciences, Debre Markos University, Debre Markos, Ethiopia. \\ SChool of Animal and Range Sciences, Haramaya University, Haramaya, Ethiopia. \\ Department of Agriculture Environment and Food, University of Molise Via Francesco De Sanctis s.n.c. 86100 Campobasso, Italy.
}

*Corresponding author: michaelabera76@gmail.com

\begin{abstract}
This study aimed to assess the impact of climatic variability on the growth performance of the Fogera cattle at Metekel cattle breeding and multiplication ranch. About 15-years of meteorological data were collected from National Meteorological Agency. Then, the heat stress (HS) condition of the ranch location was calculated by the temperaturehumidity index (THI). Moreover, all animals born and calves that were weaned from 2005 to 2019 were included in this study. Seasons and years of birth were fitted as predictors, while growth parameters were fitted as response variables. Data were analyzed by least-squares means analysis of variance using R software version 3.5.2 program. Moreover, a multiple linear regression model was also used. The trends in birth weight (BW) and weaning weight (WW) of calves were significantly decreasing along the study period. The result also indicated that the relative humidity and ambient temperature regression coefficient was negative for BW and WW. The Pearson correlation coefficient also indicated there was a negative relationship between growth parameters and climatic variables. When $\mathrm{THI}$ increases from 67 to 72 , the BW and WW of the calves were decreased by 3.5 and $25 \mathrm{~kg}$, respectively. However, the optimum THI for higher BW and WW was less than or equal to 67. The lower BW and WW of calves observed in this study is due to the cumulative effect of the climate conditions of the study area and herd management practices. Therefore, in any improvement to be made in the ranch, environmental factors should be considered along with necessary amelioration activities.
\end{abstract}

Keywords birth weight, heat stress, temperature-relative humidity index, weaning weight

\section{Introduction}

Climate change and associated weather variability are some of the factors that negatively affect agriculture production in the world (Nanganga and Safalaoh 2020). Although livestock production is a key livelihood and resilience asset of smallholder farmers, more emphasis is placed on the effects of climate change and variability on crop production than on livestock production. In Ethiopia, cattle act as a moving bank and are sold as a coping strategy to reduce the adverse effects of climate change and variability, such as prolonged droughts (Zeleke et al 2021). It is generally accepted that cattle begin to experience heat stress (HS) when the temperature-humidity index (THI) exceeds 72 (Broucek et al 2008). Fogera cattle breed is among 28 (Abraham and Abebe 2018) recognized indigenous cattle breed in Ethiopia, that is reared in districts found around Lake Tana, and is one of the main populated and productive breeds in the region (Addisu et al 2010) and in the country (DAGRIS 2007). The breed is kept at Metekel Ranch and Andassa Livestock Research Center (ALRC) for the past 28 and 52 years, respectively (Tesfa et al 2016a). The breed is also known for its tolerance to high altitudes, parasite and disease infestation, fly burden, wet soils or swampy areas, low quality of feed, and other unfavorable environmental conditions (Alberro and Haile-Mariam 1982). The breed is generally large, being tall with long legs. A massive body with solid strong bones is one of the breed's main features (DAGRIS 2007). Alberro and Haile-Mariam (1982) classified the breed as an intermediate Zebu-Sanga type, which is developed out of interbreeding of Abyssinian Zebu from central highlands and the adjacent Sanga (Danakil, Raya-Azebo). However, the population number of the breed is declining through time due to its wide-area distribution in the region and genetic admixture (Tesfa et al 2016b).

Different studies have been conducted to evaluate the genetic parameters of growth and reproductive traits of Fogera cattle, and it's crossbred at Metekel Ranch and its surrounding (Bitew and Hegde 2002; Menale et al 2011; Zeleke et al 2016a; Tesfa et al 2017; Bekele et al 2017). However, there is a paucity of information on the effects of ambient temperature (AT), relative humidity $(\mathrm{RH})$, and temperature-humidity index (THI) due to climate variability on growth parameters such as birth weight (BW) and weaning weight (WW) of the breed. For instance, $\mathrm{THI}$ is the widely used index to measure the magnitude of heat stress (HS) in animals (Dash et al 2016). However, some studies show that THI values only serve as a rough measure of HS effect on production (Polsky et al 2017). They call for necessary adjustments because the environmental stimulus 
includes other factors such as wind speed and solar radiation (Mader et al 2006).

Moreover, the THI threshold for calves and heifers remains unknown because of the very limited information available related to $\mathrm{THI}$ and HS on calves. Therefore, more studies will help to quantify THI for calves and even explore new indices to indicate the level of HS (Wang et al 2020). The hypothesis of the proposed study was changing $\mathrm{AT}, \mathrm{RH}$, and THI would affect BW and WW of the calves. Thus, the study was aimed to assess the impact of climatic variabilities such as AT, RH, and THI on BW and WW of Fogera cattle at Metekel Ranch.

\section{Materials and methods}

\subsection{Description of the study area}

The study was carried out in Metekel ranch, which is located in Guangua district of Awi zone in Amhara National Regional State and is situated at about $505 \mathrm{~km}$ North-west of Addis Ababa, and $200 \mathrm{~km}$ from the regional town Bahir Dar on the road to Guba, where Grand Ethiopian Renaissance Dam (GRED) is located. Metekel ranch is located at $10^{\circ} 57^{\prime} 6.5232^{\prime \prime} \mathrm{N}$ latitude and $36^{\circ} 30^{\prime} 45.0864^{\prime \prime} \mathrm{E}$ longitude. Its altitude ranges from 1500-1680 meter above sea level (m.a.s.l). The ranch was established in 1986 for the Fogera cattle conservation and improvement program. The vegetation is mostly composed of perennial and annual grasses and a few scattered trees. The annual mean $\mathrm{RH}$ is $61.7 \%$, and it reaches high from June to October (76.7$83.8 \%)$. The ranch receives an average annual rainfall of 1730 $\mathrm{mm}$, and the average temperature ranges from 13.7 to $29.5^{\circ} \mathrm{C}$ (ENMA, 2010). Rainfall distribution is bi-modal. According to Ababa (2007), the study area has three seasons classified as the dry season (October-January), short rainy season (February-May), and long rainy seasons (June-September).

\subsection{Herd management}

The ranch has been engaged in the maintenance of the Fogera cattle population outside their adapted environment. According to MRCMIC (2021), the farm has about 1250 cattle population. The cattle-herding system is based on breed and age. During the daytime, animals graze on natural pasture and supplemented with hay during the dry season. Calves above three months of age and sick animals are supplemented with green feed such as desmodium (Desmodium triflorum), rehodus (Chlorisgayana), and elephant grass (Pennisetum purpureum) in dry seasons through a cut and carry system. In addition to this, $0.5 \mathrm{~kg}$ concentrate mixtures consist of $55 \%$ maize, $26 \%$ noug seed cake, $17 \%$ wheat bran, $1 \%$ salt, and $1 \%$ ruminant premix (minerals and vitamins) mixtures, are supplemented per cow per day during the dry and short rainy season period. The main source of water is a year-round river. Tap-water has been provided to lactating Fogera cows, crossbred stock, and sick animals. Health management practice includes the prevention and control scheme. The prevention scheme focused on vaccination against anthrax, blackleg, and pasteurellosis once every 6 to 8 months and once per year for CBPP. Whereas, control measures focused on internal and external parasites. De-worming is conducted twice a year, at the start and end of the rainy seasons. For ease of herd, management animals were kept at three sites. On the ranch, calves were weighed on the date of birth and identified within 72 hours of birth. Calves were weaned, and WW was recorded at eight months of age.

\subsection{Breeding program}

The breeding program has two components: selection and crossbreeding. The establishment of the pure breed unit is meant to improve the Fogera cattle breed and provide heifers for crossbreeding to exotic dairy sires (by Artificial insemination). In the pure breed unit selection program, the tradition is Fogera bulls are allowed to run together with Fogera cows. The selection activity undertaken at Metekel ranch had never been based on quantitative traits; instead, the visual appraisal had been used (Zeleke et al 2016a). But recently, they have been trying to study and include the background of the animal during selection. The main objectives of the ranch are (1) Fogera cattle conservation and (2) breed improvement both through selection and crossbreeding (MRCMIC 2021).

\subsection{Meteorological variables}

For this study, 15-years (2005-2019) period meteorological data such as daily minimum and maximum AT, minimum and maximum $\mathrm{RH}$ were collected from National Meteorological Agency, a weather station near the ranch (Zewdu et al 2014). Then, the HS condition of the ranch location was calculated by the temperature-humidity index $(\mathrm{THI})$, as $\mathrm{THI}=(1.8 * \mathrm{AT}+32)-\left[\left(0.55-0.0055^{*} \mathrm{RH}\right) \times\left(1.8^{*} \mathrm{AT}-26\right)\right]$ developed by the NRC (1971) for ruminant animals. Where; $\mathrm{AT}=$ ambient temperature $\left({ }^{\circ} \mathrm{C}\right)$, and $\mathrm{RH}=$ relative humidity (\%) and $\mathrm{THI}=$ temperature-humidity index. Then, the classification reported by Habeeb et al (2018) was adopted to quantify the intensity of HS in Fogera cattle. Thus, they were assumed to be in comfort zone if $(\mathrm{THI}<68)$, mild discomfort zone if $(68<\mathrm{THI}<72)$, discomfort if $(72<\mathrm{THI}<75)$, alert $(75$ $<\mathrm{THI}<79)$, danger $(79<\mathrm{THI}<84)$, and emergency $(\mathrm{THI}>84)$. 2.4.2. Birth weight and weaning weight

All records of animals born and cows that calved between 2005 and 2019 were included in this study. To analysis, the effect of season on BW, the fixed effect of calving/birth seasons was classified as long rainy season (June-September), short rainy season (February-May), and dry season (October-January) following NMA (2007). Likewise, to analyze the effect of season on WW, the fixed effect of weaning seasons was classified as long rainy season (June-September), short rainy season (February-May), and dry season (October-January). During this time, records with irregularity in pedigree information and dates were discarded. The animals with abnormal calving, i.e., abortion and stillbirths, were not included in the analysis. The WW of calves was recorded at eight months of age. After clearing BW 
and WW data for consistency of pedigree information, a final data was used for the analysis.

\subsection{Statistical analysis}

Both growth and meteorological data were analyzed by least-square means analysis of variance techniques using $\mathrm{R}$ software version 3.5.2 program. Moreover, the ggscatter plot was done to show the relationship between $\mathrm{THI}$ and growth parameters using $\mathrm{R}$ softer ware in the package ggpubr. For the analysis of BW, and WW; year of birth (YB) and season of birth (SB) were fitted as fixed effects while BW and WW were fitted as response variables. Thus, the following mathematical model was employed to analyze BW: $Y_{i j k}=\mu+X_{i}+S_{j}+e_{i j k}$, where, Yijk $=k^{\text {th }}$ record of BW in the $i^{\text {th }}$ year, and $j^{\text {th }}$ season, $\mu=$ overall mean, $X_{i}=$ effect of $i^{\text {th }}$ year of birth ( $i=2005-2019), S_{j}=$ effect of $j^{\text {th }}$ season of birth $(j=1,2$, 3), $\mathrm{e}_{i j \mathrm{k}}=$ random error associated with each observation. Moreover, the following mathematical model was employed to analyze WW:

$\mathrm{Y}_{i j k}=\mu+\mathrm{X}_{i}+\mathrm{S}_{\mathrm{j}}+\mathrm{e}_{i j k}$

where, Yijk $=k^{\text {th }}$ record of WW in the $i^{\text {th }}$ year, and $j^{\text {th }}$ season, $\mu$ $=$ overall mean, $X_{i}=$ effect of $i^{\text {th }}$ year of birth ( $\left.i=2005-2019\right)$, $\mathrm{S}_{j}=$ effect of $j^{\text {th }}$ season of birth $(j=1,2,3), e_{i j k}=$ random error associated with each observation.

A multiple regression model was used to investigate the effect of climatic variables on growth parameters (BW, and $W W$ ). The following regression model was utilized to study the effect of different independent variables such as AT, RH, and THI on BW: $Y=\mu+b_{1} X_{1}+b_{2} X_{2}+b_{3} X_{3}+e i j$, where; $Y$ is the dependent variable (BW), $X$ is the independent variable (AT, RH and THI), $\mu$ is the overall mean, $b$ is the coefficients of $X$ and $e_{i j}$ is an error term. Likewise, the following regression model was utilized to study the effect of different independent variables such as $\mathrm{AT}, \mathrm{RH}$, and THI on WW: $\mathrm{Y}=\mu+$ $b_{1} X_{1}+b_{2} X_{2}+b_{3} X_{3}+e i j$, where; $Y$ is the dependent variable (WW), $X$ is the independent variable (AT, RH and THI), $\mu$ is the overall mean, $b$ is the coefficients of $X$ and $e_{i j}$ is an error term. These multiple regression equations describe an average relationship between dependent and independent variables used to predict the dependent variables. The variability of the model was tested with the help of the coefficient of determinations $\left(R^{2}\right)$. The significance of $R^{2}$ was tested with the F-test and the significance of the individual regression coefficient was tested with students't test.

\section{Results and Discussion}

\subsection{Patterns of the climatic variability during the study periods}

The study revealed that the mean annual AT trend in the study area was significantly increased during the study period (Figure 1). The increase in mean annual AT was attributed to climate change which directly affects the animals in terms of growth and reproductive performance. Furthermore, the increase in annual mean AT is responsible for water scarcity, especially during the dry and short rainy seasons. Abera et al (2020) also reported that the mean annual AT in the study area was significantly increasing. Similarly, most of the previous studies in this region (Mengistu et al 2014; Alemayehu and Bewket 2017; Asfaw et al 2018) and in Ethiopia in general (Addisu et al 2015) also confirmed the presence of significant increasing trends in temperature.

The mean annual RH was also significantly increasing in the study area (Figure 1). As the years advanced from 2005 to 2019 , the RH was increased by $9.7 \%$, which needs great intervention to reduce the effect of HS under future climate change. According to NRC (2011), the acceptable range of RH is $30-70 \%$ for most mammalian species. High RH affects animal bedding, which results in increased litter moisture and ammonia concentrations. This exacerbates the negative effects of humidity on animal growth performance and carcass characteristics (Weaver and Meijerhof 1991). The study revealed that almost all of the annual mean $\mathrm{RH}$ observations were above the acceptable range (Figure 1). The increase in annual mean $\mathrm{RH}$ suggests that the climate change directly affects the animal's comfort zone through uplifting THI which can be mainly explained in terms of HS. The study also revealed that $\mathrm{THI}$ was significantly increasing with advancing in years (Figure 1). According to Habeeb et al (2018), the mean annual THI in the current study was below the critical value for HS from 2005 to 2012. However, it was in HS condition since 2013. The increase in THI was emanated from an increase in mean annual AT and RH over time. The rise in $\mathrm{THI}$ value above the comfort zone affects the animals in different ways, such as reducing feed intake, which directly affects weight gain, rectal temperature, sweating rate, heart rate, and respiration rate.

Moreover, the increase in THI directly affects the health condition of the animals. This also indicates the need to made great interventions such as appropriate feeding, provision of shade, water, and selecting the best performing indigenous breed at higher THI. A similar result was reported by Abera et al (2021) in Fogera cattle calves under the same environment.

\subsection{Trends of climatic variability and birth weight}

The BW of Fogera cattle trends are significantly decreasing through time from 2005 to 2019, as shown in Figure 2. Results of least squares means showed that BW was quickly reducing through the years. This might be due to poor management practices such as health care, housing condition, low concentrate supplementation, inconsistency in management, and an increase in THI over the years that affected the dams, indirectly contributing to a decrease in BW. Yaylak et al (2015) reported variations in BW of calves were mainly because of climate conditions, housing conditions, feeding, and herd management practices of the dams during gestations. The result is also in line with Zeleke et al (2016a), who reported that BW was deteriorating through years from 1990 to 2012 in Fogera X Holstein Frisian crossbred in the same environment. The result also revealed that as BW of Fogera cattle was a decline from 2005 to 2019 
while THI was increasing simultaneously. The decrease in BW when $\mathrm{THI}$ increase might be due to the direct effect of $\mathrm{THI}$ on the dam during the pregnancy period, such as reduction in feed intake, which resulted in lower BW of the calves. It is known that animals that are exposed to high AT augment the efforts to dissipate body heat, increased respiration rate, body temperature, and consumption of water, and a decline in feed intake (Marai et al 2007, Sejian et al 2010). Padua et al (1997) also reported that feed conversion also significantly decreases after exposure to HS apart from feed intake.

Moreover, Marai et al (2007) indicated that exposure of the animal to a high AT stimulates the peripheral thermal receptors to transmit suppressive nerve impulses to the appetite center in the hypothalamus and thereby causes a decrease in feed intake. The reduction in feed intake could be due to the adaptive mechanism of animals to produce less body heat (Veerasamy et al 2015). In studies conducted for the removal of adverse effects of HS on BW by shade and sprinkle on dairy cattle with Holstein blood in the dry period, it is seen that BW decreased about $8-12 \%$ in counter groups
(Collier et al 1982; Wolfenson et al 1988; Avendaño-Reyes et al 2006). The present result showed that when THI increases from 67 to 72 , the BW of the calves was decreased by $3.5 \mathrm{~kg}$ (Figure 2). When the results of the current study were compared with the results of the study on the Holstein breed (Collier et al 1982; Wolfenson et al 1988; Avendaño-Reyes et al 2006), it can be concluded that the decrease in BW due to THI was lower than the one reported for Holstein Friesian's. Thus, this result is thought to be due to Fogera's better adaptation ability to hot climates (Abera et al 2021).

Moreover, this result further confirmed that the heat tolerance ability of indigenous breeds over exotic ones. However, further improvement in feeding, health care, and amelioration strategies such as the provision of shade and frequent watering during short rainy and dry seasons should withstand the impact of the anticipated climate change. A similar study in India also indicated a significant negative relationship between growth parameters and $\mathrm{THI}$ in crossbred cattle calves (Aziz et al 2016).

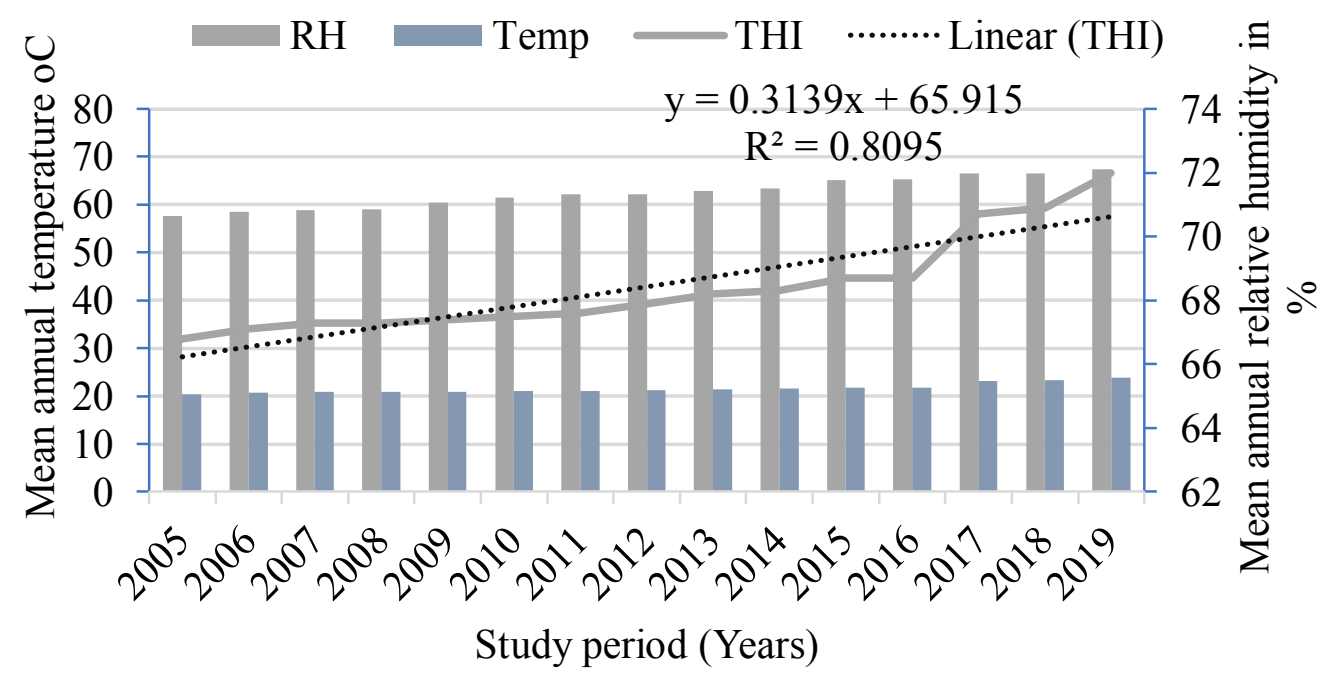

Figure 1 Patterns of climatic variables during the study period (2005-2019).

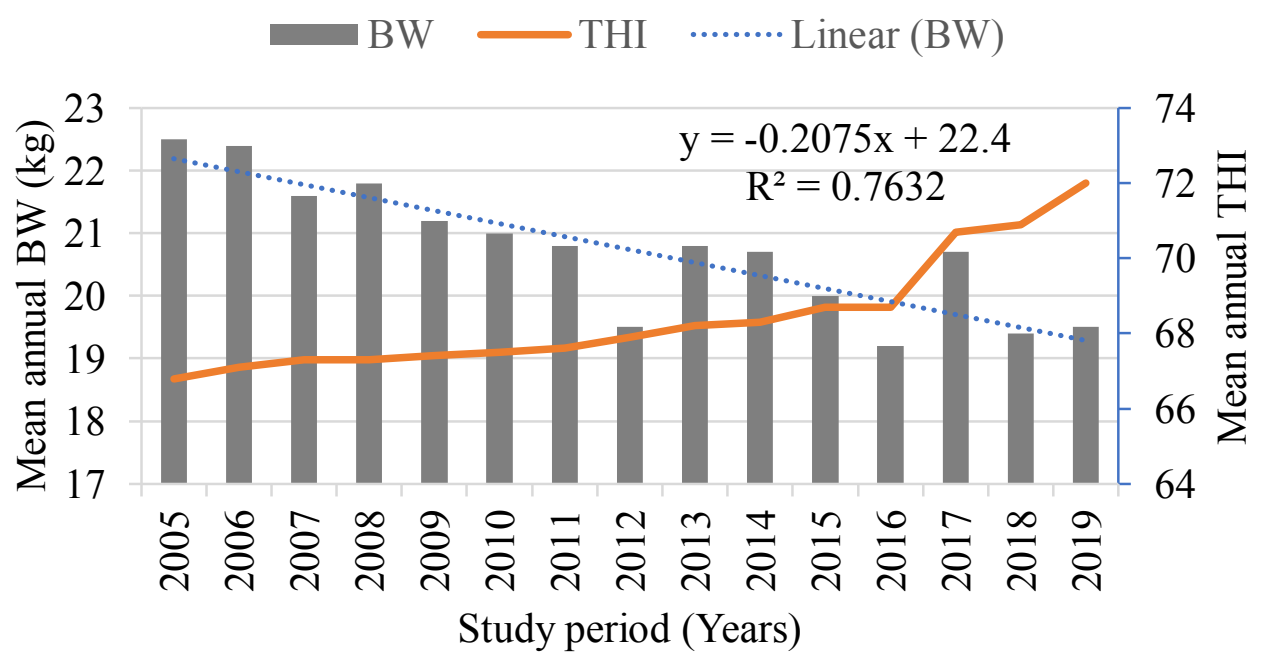

Figure 2 Trends in mean annual birth weight and THI over the last 15-years (2005-2019). 


\subsection{Regression and correlation analysis of birth weight and} climatic variables

Exposure of animals to hot or cold stress reduces growth and feed efficiency (Ames 1980). The multiple linear regression analysis showed that the BW of calves was significantly affected by $\mathrm{RH}$ (Table 1 ). The result indicated that the regression coefficient of $\mathrm{RH}$ and AT was negative for $\mathrm{BW}$. The negative regression coefficient for BW indicated as the $\mathrm{RH}$ and $\mathrm{AT}$ increases, the BW of calves were decreasing years after years. Moreover, the Pearson correlation coefficient indicated that there was a negative and significant relationship between BW and all climatic variables considered in this study. Figure 4 also shows that there was a negative and significant relationship between the mean annual THI and BW of the calves ( $r=-0.68, p=0.0052)$.

Moreover, Figure 3 indicated that the mean annual $\mathrm{BW}$ of the calves started to decline at or greater than the THI value of 67 . The coefficient of determination $\left(R^{2}\right)$ also showed that all the climatic variables together were accounted for 73\% variation in BW while other unexplained factors contributed to the rest of the variations. The coefficient of determination $\left(R^{2}\right)$ value showed significance at $p<0.001$ level. This illustrated that BW was mainly influenced by climatic variables than unexplained variables such as feeding, health care, etc. Thus, it can be inferred that BW was the most heat-sensitive growth parameter. Yaylak et al (2015) also found that the BW of calves with low THI values during the last trimester of gestation period was higher than the calves with high $\mathrm{THI}$ values throughout the same period. The decrease in BW of calves with an increase in THI, RH, and AT might be due to the direct effect of these parameters on the dam, which indirectly resulted in low BW of the calves. It is known that in rats, sheep, and cattle exposed to HS during pregnancy retrogression of fetal growing and decrease in BW occurs (Brown et al 1977, Collier et al 1982). Unlike the current result, Ugurlu et al (2014) observed that BW was not significantly affected by THI in Jersey's calves in Turkey.

Table 1 Regression and correlation analysis of birth weight and climatic variables (2005-2019)

\begin{tabular}{lcccccc}
\hline \multicolumn{7}{c}{ Birth weight $(\mathrm{kg})$} \\
\hline Variables & $\mathrm{LSM} \pm \mathrm{SE}$ & $\mathrm{r}$ & $\mathrm{b}$ & $\mathrm{SE}(\mathrm{b})$ & $\mathrm{t}$-value & $P(>|\mathrm{t}|)$ \\
\hline $\mathrm{RH}(\%)$ & $62.50 \pm 0.82$ & $-0.86^{* *}$ & -0.4 & 0.11 & $-4.04^{* *}$ & 0.00211 \\
Temp $\left({ }^{\circ} \mathrm{C}\right)$ & $21.59 \pm 0.28$ & $-0.69^{* *}$ & -0.3 & 1.89 & $0.17^{\mathrm{NS}}$ & 0.86497 \\
$\mathrm{THI}$ & $68.43 \pm 0.40$ & $-0.68^{* *}$ & 0.11 & 1.28 & $0.10^{\mathrm{NS}}$ & 0.92974 \\
\hline
\end{tabular}

Adjusted $\mathrm{R}^{2}=0.73$

$\mathrm{F}=13.4^{* * *} \quad P=0.0005416$

$\mathrm{RH}=$ mean annual relative humidity, Temp = mean annual temperature $\left({ }^{\circ} \mathrm{C}\right), \mathrm{THI}=$ mean annual temperature-humidity index, $\mathrm{r}=\mathrm{Pearson}$ correlation coefficient, $\mathrm{b}=$ regression coefficient, $\mathrm{SE}=$ standard error of regression coefficient, ${ }^{* *}$ and ${ }^{* * *}$ are significant at 0.01 and 0.001 while Ns $=$ nonsignificant at $0.05 \mathrm{p}$-levels, respectively.

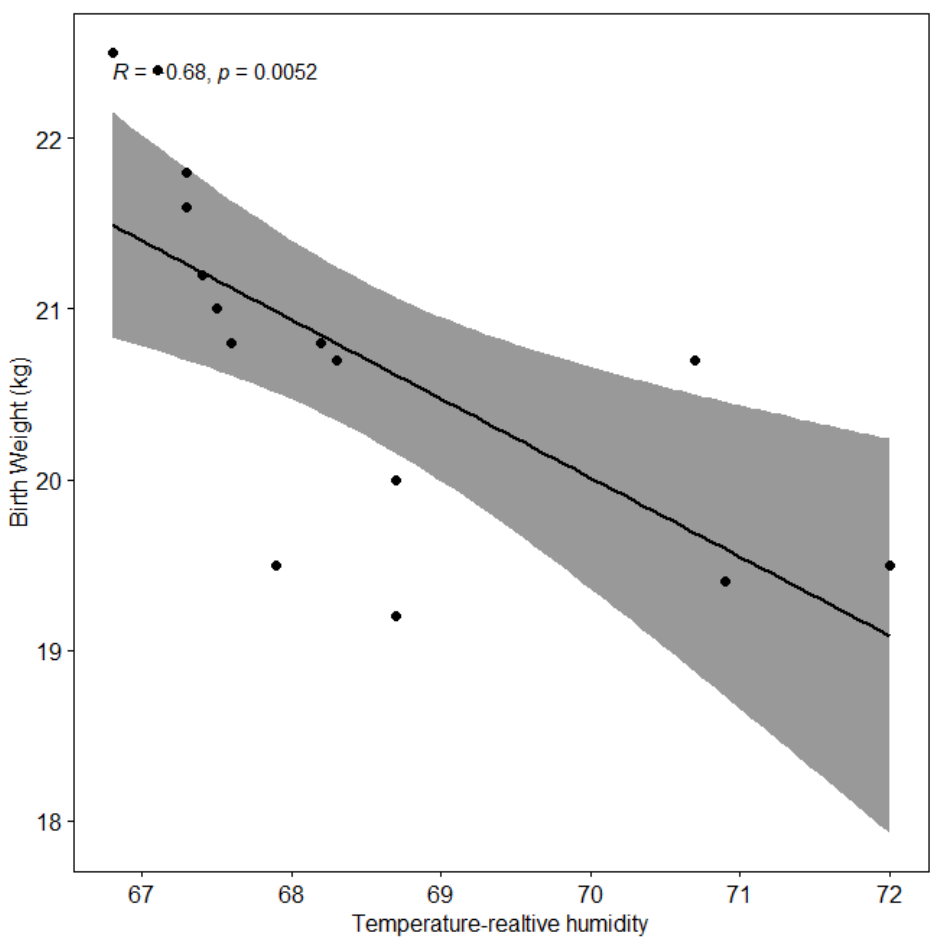

Figure 3 Relationship between mean annual THI and BW (2005-2019). 
3.4. Trends of Temperature-humidity index and weaning weight in Fogera cattle

The study showed WW of Fogera cattle was noticeably decreasing while THI was increasing year after year during the study periods (Figure 4). The decrease in WW might be due to a decline in health care management practices, concentrate supplementation, availability of natural pasture, green fodders, and an increase in environmental AT through time. Habeeb (1992) and Ismail et al (1995) reported elevated AT is considered to be one of the environmental factors influencing growth and average daily gain (ADG) in livestock. The reason for the effects of elevated AT on growth reduction could be due to the decrease in anabolic activity and the increase in tissue catabolism (Marai et al 2007). The increase in tissue catabolism could be attributed to increased catecholamines and glucocorticoids after exposure to HS in livestock. Moreover, the decline in WW in the ranch might be due to inconsistency of management over the years that affected the calves WW. The current result is in line with the findings of Zeleke et al (2016b) who reported a reduction of WW years after years for Fogera $X$ Holstein Frisian crossbred at Metekel ranch. The decline in WW over time might be also due to poor management and failure of selection in the ranch.

The result showed when THI increase from 67 to 72, the WW of the calves was decreased by $25 \mathrm{~kg}$ (Figure 4). The decrease in WW with an increase in THI might be due to the direct effect of this parameter on the calves, affecting their feed intake, availability of natural pasture and making them vulnerable to certain diseases. Moreover, as HS due to THI increases, animals may use their energy for hemostasis instead of growth to maintain their internal temperature. As ambient heat load increases, cattle divert energy that is typically partitioned for growth towards maintaining homeostasis (Ravagnolo and Misztal 2002; Kadzere et al 2002), resulting in a reduction in growth and growth efficiency in lactating dairy cows. A study in Japanese black calves also showed that a higher mean THI during the third month after birth was associated with a lower birth weight gain (BWG) at the calf market, and BWG with $\mathrm{THI}$ of $>75$ was significantly lower than that with $\mathrm{THI}$ of $\leq 50$ or $\mathrm{THI}$ ranging from 56 to 60 (Nabenishi and Yamazaki 2017). Similarly, Colditz and Kellaway (1972) showed that heifers raised under $\mathrm{HS}$ conditions ( $38^{\circ} \mathrm{C}$ environments) had reduced feed intake and ADG compared to those maintained under cool ambient conditions $\left(17^{\circ} \mathrm{C}\right.$ environments) in Friesian, F1 Brahmanx Friesian, and Brahman heifers. Baccari et al (1983) also reported lower feed intake, ADG, and feed efficiency of Holstein heifers under $\mathrm{HS}$ conditions $\left(32.5\right.$ to $34^{\circ} \mathrm{C}$ environment) compared with cooler conditions ( 18 to $20^{\circ} \mathrm{C}$ environment). Therefore, from this result, it can be generalized that the appropriate THI for higher WW is less than or equal to 67, consistent with Abera et al (2021).

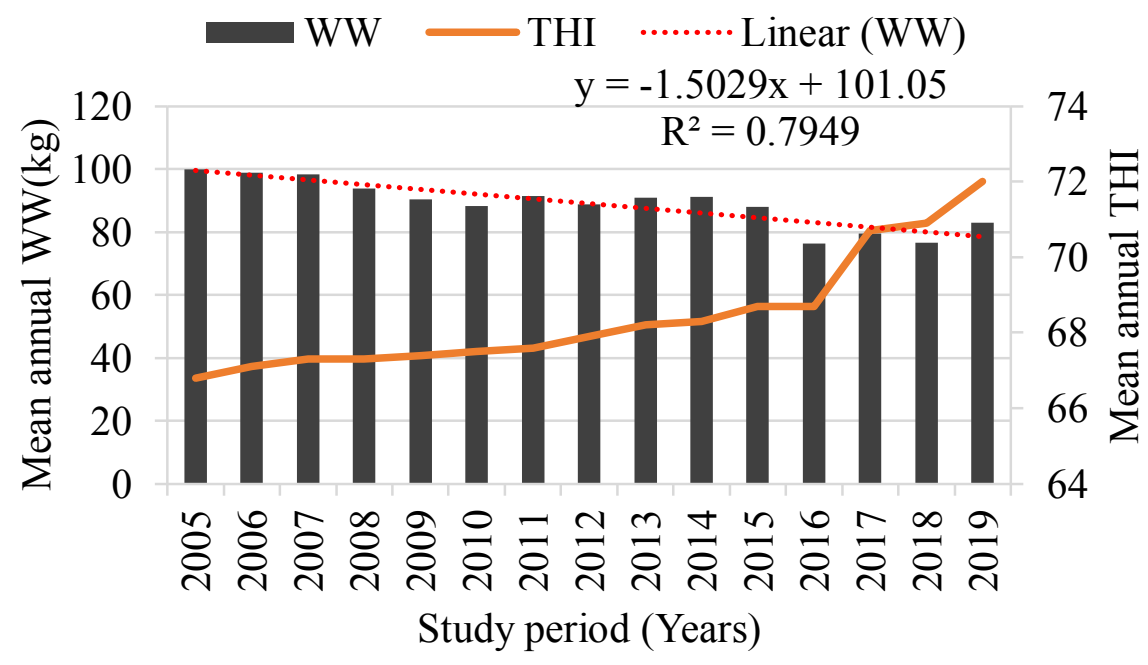

Figure 4 Trends in mean annual weaning weight of Fogera cattle and THI over the last 15-years (2005-2019).

\subsection{Regression and correlation analysis of climatic variability} on weaning weight

The multiple linear regression analysis showed that WW of calves was significantly affected by RH (Table 2). The result indicated that the regression coefficient of $\mathrm{RH}$ and $\mathrm{AT}$ was negative for WW. The negative regression coefficient for WW indicated that the WW of calves decreased as the $\mathrm{RH}$ and AT increased. Moreover, the coefficient of determination $\left(R^{2}\right)$ showed that all the climatic variables together were accounted for $83 \%$ variation explained in WW. The Pearson correlation coefficient also indicated that there was a negative and significant relationship between WW and climatic variables. Figure 5 also shows that there was a negative and significant relationship between the mean annual THI and WW of the calves $(r=-0.78, p=0.00062)$. The Figure also clearly indicated that the WW of calves were decreasing after THI greater than or equal to 67. The negative relationship between $\mathrm{WW}$ and climatic variables might be due to the direct effect of these variables on the calves during high environmental AT in the ranch, especially during the dry 
and short rainy seasons. The adverse effect of this high AT and $\mathrm{RH}$ might be increasing the rectal temperature, respiration rate, sweating rate, and declining the feed intake calves. This result confirms that WW is mainly influenced by climatic variables than other management practices in the study area. A similar study in India indicated a significant negative relationship between growth parameters and $\mathrm{TH}$ in crossbred cattle calves (Aziz et al 2016).

Moreover, Ames (1980) observed that exposure of animals to hot or cold stress reduces growth and feed efficiency. Abera et al (2021) also reported that at higher environmental THI, the ADG and final body weight (FBW) of the calves were significantly affected in the same breed at Metekel ranch. Similarly, Nabenishi and Yamazaki (2017) indicated that Japanese black calves are susceptible to a cold environment immediately after birth, while they are susceptible to a heat environment 3 months after birth. Furthermore, Yaylak et al (2015) reported that WW decreased with increasing THI values and vice versa in Izmir cattle breeders' association.

Table 2 Regression and correlation analysis of birth weight and climatic variables (2005-2019).

\begin{tabular}{lcccccc}
\hline \multicolumn{7}{c}{ Weaning weight $(\mathrm{kg})$} \\
\hline Variables & $\mathrm{LSM} \pm \mathrm{SE}$ & $\mathrm{r}$ & $\mathrm{b}$ & $\mathrm{SE}(\mathrm{b})$ & $\mathrm{t}$-value & $P(>|\mathrm{t}|)$ \\
\hline $\mathrm{RH}(\%)$ & $62.50 \pm 0.82$ & $-0.9^{* * *}$ & -2.15 & 0.62 & $-3.46^{* *}$ & 0.00531 \\
Temp(oC) & $21.59 \pm 0.28$ & $-0.8^{* * *}$ & -22.7 & 10.76 & $-2.11^{\mathrm{NS}}$ & 0.05873 \\
$\mathrm{THI}$ & $68.43 \pm 0.40$ & $-0.78^{* *}$ & 15.73 & 7.23 & $2.176^{\mathrm{NS}}$ & 0.05223 \\
\hline & & $\mathrm{R}^{2}=0.83$ & $\mathrm{~F}=23.1^{* * *}$ & & $P=4.74 \mathrm{e}-05$ \\
\hline
\end{tabular}

$\mathrm{RH}=$ annual mean relative humidity, Temp $=$ annual mean temperature $\left({ }^{\circ} \mathrm{C}\right), \mathrm{THI}=$ annual mean temperature-humidity index, $\mathrm{r}=\mathrm{Pearson}$ correlation coefficient, $\mathrm{b}=$ regression coefficient, $\mathrm{SE}=$ standard error of regression coefficient, $* *$, and $* * *$ are significant at 0.01 and $0.001 \mathrm{p}$ level, respectively while $\mathrm{Ns}=$ nonsignificant at $0.05 P$-level.

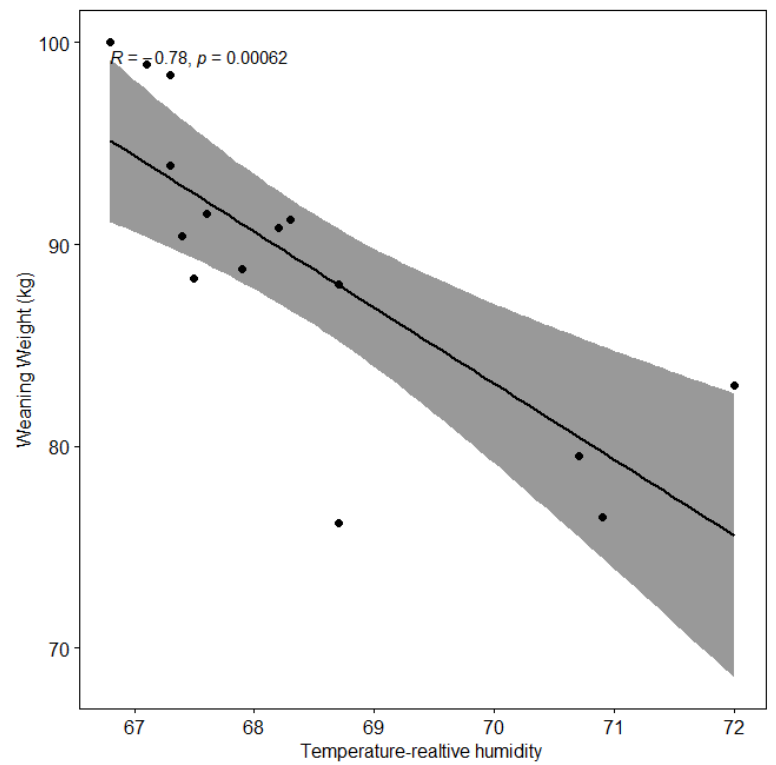

Figure 5 Relationship between mean annual weaning weight of Fogera cattle and THI over the last 15-years (2005-2019).

3.6. Effect of climatic variables on growth performance of Fogera cattle during different seasons

The study showed season of birth had no significant effect on BW while it was significantly influenced the WW of calves. In agreement with the current result, Ugurlu et al (2014) reported that season had no significant effect on BW in Jersey's calves in Turkey. Higher WW was observed during short and long rainy seasons compared to the dry season, as shown in Figure 6. During the long rainy season, there was a higher maximum RH but lower AT and THI. On the other hand, there was lower maximum $\mathrm{RH}$ during dry and short rainy seasons but higher AT, which leads to a higher maximum THI than the long rainy season (Figure 6). A study in Turkey also showed that THI was the highest for summer than that of the winter while the cold stress index was the highest for winter than that of the summer in Jersey calves (Ugurlu et al 2014). Thus, because of the availability of natural pasture and relatively better environmental temperature, the long rainy season was the most promising season for maximum WW.

Moreover, from this result, it can be deduced that AT was the most dominant environmental factor that can determine the performance of the animals. The lower WW during the dry season may be due to a shortage of natural pasture and high AT that decreases feed consumption of calves. This suggests that the variation in AT and other 
environmental conditions among birth years significantly affected the calves at Weaning in Holstein's calves (Yaylak et al 2015). The decline in the WW with higher THI might be because calves dissipate heat from their body to adapt to the increase in $\mathrm{THI}$, especially during the dry and short rainy season. Moreover, the decrease in growth rate with the rise in THI might be because animals used most of the energy to maintain their homeothermy instead of growth (Aziz et al 2016).

$$
\text { - Dry } \square \text { Short } \square \text { Long }
$$

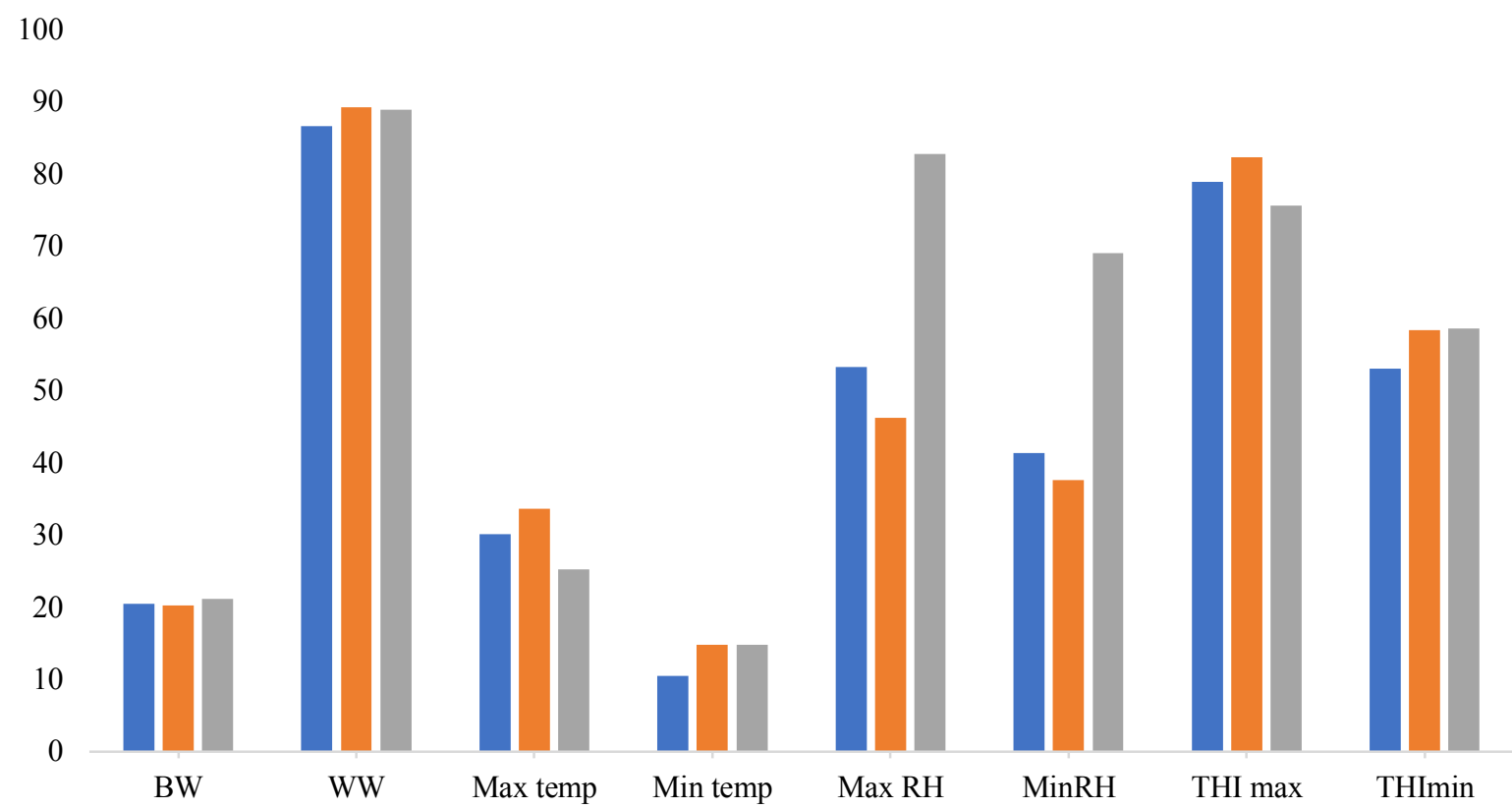

Figure 6 Relationship between growth parameters and climatic variables at different seasons (2005-2019). BW = birth weight, WW = weaning weight, Max temp = maximum temperature, Min temp= maximum temperature, $\mathrm{Max} \mathrm{RH}=$ maximum relative humidity, $\mathrm{Min} \mathrm{RH}=$ minimum relative humidity, $\mathrm{THI} \max =$ maximum temperature-humidity index and THI $\min =$ minimum temperature-humidity index.

\section{Conclusions}

The result revealed that BW and WW of Fogera cattle at Metekel ranch decreased over time from 2005 to 2019. BW and WW in this study were lower than the previous studies reported for the same breed at different locations. The variation among the reports for the same breed might be due to the difference in location and some environmental effects. Moreover, the variation was due to feed availability, AT, and related to management differences. Our study also found that there was a negative relationship between growth parameters and THI. When THI increases from 67 to 72, the BW and WW of the calves were decreased by 3.5 and $25 \mathrm{~kg}$, respectively. The decrease in $\mathrm{BW}$ of calves with an increase in $\mathrm{THI}, \mathrm{RH}$, and AT might be due to the direct effect of these parameters on the dam. Thus, this effect also indirectly resulted in low BW of the calves. The decrease in WW with an increase in $\mathrm{THI}, \mathrm{RH}$, and $\mathrm{AT}$ is due to the direct effect of these parameters on the calves, affecting their feed intake, availability of pasture, and making them vulnerable to certain diseases. Therefore, more attention should be given to climatic variables in line with other management practices to increase the BW and WW of the calves at Metekel ranch. This study also indicated that at lower THI values, animals showed higher BW and WW. Therefore, a THI value of less than or equal to 67 for BW and WW can be considered optimum at their current production environment. However, the provision of proper health care and feeding practices may also improve the current lower BW of the calves. This study shows that the lower BW and WW of calves observed in this study is mainly because of the cumulative effect of the climate conditions of the study area, housing conditions, feeding, and herd management practices of the ranch. Therefore, in any improvement to be made in the farm, such effects of environmental factors should be considered along with necessary amelioration activities.

\section{Acknowledgments}

The authors are grateful to Metekel ranch and the National Meteorological Agency for providing us 15 years of growth and climate data, respectively. Moreover, the livestock experts at Metekel ranch who participated in the data collection are also highly appreciated and acknowledged.

\section{Conflict of Interest}

The authors declare that they have no conflict of interest.

\section{Funding}

Africa Centre of Excellence for Climate Smart Agriculture and Biodiversity Conservation, Haramaya University, and Debre Markos University funded this research as part of a Ph.D. study. 


\section{References}

Ababa A (2007) Climate change national adaptation programme of action (Napa) of Ethiopia. National Meteorological Services Agency, Ministry of Water Resources, Federal Democratic Republic of Ethiopia, Addis Ababa.

Abera M, Mummed YY, Eshetu M, Pilla F, and Wondifraw Z (2020) Perception of Fogera Cattle Farmers on Climate Change and Variability in Awi Zone, Ethiopia. Open Journal of Animal Sciences 10:792-815.

Abera M, Yusuf Mummed Y, Eshetu M, Pilla F, and Wondifraw Z (2021) Physiological, Biochemical, and Growth Parameters of Fogera Cattle Calves to Heat Stress during Different Seasons in Sub-Humid Part of Ethiopia. Animals 11:1062.

Abraham A, and Abebe H (2018) Ethiopian indigenous cattle breed's diversity, distribution, purpose of keeping, and their potential threats. J Bio Innov 7:770 -789.

Addisu B, Adebabay K, Bewuket S, Solomon G, and Tewodros B (2010) Conservation-Based Breeding Program for Fogera Cattle. Working Document.Amhara Regional Agricultural Research Institute Andassa Livestock Research Center (unpublished paper).

Addisu S, Selassie YG, Fissha G, and Gedif B (2015) Time series trend analysis of temperature and rainfall in lake Tana Sub-basin, Ethiopia. Environmental Systems Research 4: 1-12

Alberro M, and Haile-Mariam S (1982) The indigenous cattle of Ethiopia. Part I. World Animal Review.

Alemayehu A, and Bewket W (2017) Smallholder farmers' coping and adaptation strategies to climate change and variability in the central highlands of Ethiopia. Local Environment 22:825-839.

Ames D (1980) Thermal environment affects production efficiency of livestock. BioScience 30:457-460.

Asfaw A, Simane B, Hassen A, Bantider A (2018) Variability and time series trend analysis of rainfall and temperature in north-central Ethiopia: A case study in Woleka sub-basin. Weather and climate extremes 19:29-41.

Avendaño-Reyes L, Alvarez-Valenzuela FD, Correa-Calderón A, SaucedoQuintero JS, Robinson PH, and Fadel JG (2006) Effect of cooling Holstein cows during the dry period on postpartum performance under heat stress conditions. Livestock Science 105:198-206.

Aziz Z, Varma G, Raji K, and Gleeja V (2016) Influence of temperaturehumidity index on the physiological parameters and growth rate of crossbred cattle calves. International Journal of Applied and Pure Science and Agriculture 3:187-189.

Baccari F, Johnson HD, and Hahn GL (1983) Environmental heat effects on growth, plasma T3, and postheat compensatory effects on Holstein's calves. Proceedings of the Society for Experimental Biology and Medicine 173:312 318.

Bekele A, Wuletaw Z, Haile A, Gizaw S, and Mekuriaw G (2017) Genetic parameters for reproduction traits and correlation with pre-weaning growth traits of Fogera cattle at Metekel ranch, north west Ethiopia. Livestock Research for Rural Development 29:2019.

Bitew A, and Hegde B (2002) Reproductive and growth performance of Fogera cattle and their F1 Friesian crosses at Metekel ranch, Ethiopia. Challenges and opportunities of livestock marketing in Ethiopia. Proceedings of the 10th annual conference of the Ethiopian Society of Animal Production (ESAP) held in Addis Ababa, Ethiopia, 119-131.

Broucek J, Kisac P, Uhrincat M, Hanus A, and Benc F (2008) Effect of high temperature on growth performance of calves maintained in outdoor hutches. Journal of Animal and Feed Sciences 17:139.

Brown DE, Harrison PC, Hinds FC, Lewis JA, and Wallace MH (1977) Heat stress effects on fetal development during late gestation in the ewe. Journal of animal science $44:$ 442-446

Colditz PJ, and Kellaway RC (1972) The effect of diet and heat stress on feed intake, growth, and nitrogen metabolism in Friesian, F1 Brahman× Friesian, and Brahman heifers. Australian Journal of Agricultural Research 23:717725.

Collier RJ, Doelger SG, Head HH, Thatcher WW, and Wilcox CJ (1982) Effects of heat stress during pregnancy on maternal hormone concentrations, calf birth weight and postpartum milk yield of Holstein cows. Journal of Animal
Science 54:309-319.

DAGRIS (2007) Domestic Animal Genetic Resources Information System (DAGRIS). (eds. S. Kemp, Y. Mamo, B. Asrat and Tadele Dessie). International Livestock Research Institute, Addis Ababa Ethiopia.http://dagris.ilri.cgiar.org.

Dash S, Chakravarty SA, U Manvendra S, and Saleem Y (2016) Effect of heat stress on reproductive performances of dairy cattle and buffaloes: A review. Veterinary World 9:235-244.

ENMA (2010) Ethiopian National Meteorological Agency. Annual report Habeeb AA (1992) Heat stress. Farm animals and the environment.

Habeeb AA, Gad AE, and Atta MA (2018) Temperature-humidity indices as indicators to heat stress of climatic conditions with relation to production and reproduction of farm animals. Int J Biotechnol Recent Adv 1:35-50.

Ismail E, El-Latif HA, Hassan GA, and Salem MH (1995) Water metabolism and requirements of sheep as affected by breed and season. World review of animal production.

Kadzere CT, Murphy MR, Silanikove N, and Maltz E (2002) Heat stress in lactating dairy cows: a review. Livestock production science 77:59-91.

Mader L, Davis M, and Brown-Brandl T (2006) Environmental factors influencing heat stress in feedlot cattle. Journal of Animal Science 84:712719.

Marai IFM, El-Darawany AA, Fadiel A, and Abdel-Hafez MAM (2007) Physiological traits as affected by heat stress in sheep - a review. Small Rumin Res 71:1-12

Menale M, Mekuriaw Z, Mekuriaw G, and Taye M (2011) Reproductive performances of Fogera cattle at Metekel Cattle Breeding and Multiplication Ranch, north-west Ethiopia. Journal of Animal and Feed Research 1:99-106.

Mengistu D, Bewket W, and Lal R (2014) Recent spatiotemporal temperature and rainfall variability and trends over the Upper Blue Nile River Basin, Ethiopia. International Journal of Climatology 34:2278-2292.

MRCMIC (2021) Metekel ranch cattle multiplication and improvement center report, Awi zone, Ethiopia.

Nabenishi H, and Yamazaki A (2017) Effects of the temperature-humidity index on health and growth performance in Japanese black calves. Tropical animal health and production 49:397-402

Nanganga J, and Safalaoh AC (2020) Climate Change and Weather Variability Effects on Cattle Production: Perception of Cattle Keepers in Chikwawa, Malawi. Climate Impacts on Agricultural and Natural Resource Sustainability in Africa. Springer.

NMA (2007) Climate change national adaptation program of action of Ethiopia, edited by Abebe, T. Addis Ababa, Ethiopia.

NRC (1971) A guide to environmental research on animals, National Academies.

NRC (2011) Guide for the care and use of laboratory animals: Washington DC: The National Academies Press.

Padua JT, Dasilva RG, Bottcher RW, and Hoff SJ (1997) Effect of high environmental temperature on weight gain and food intake of Suffolk lambs reared in a tropical environment. In: Proceedings of 5 th international symposium, Bloomington, Minnesota, USA 809-815.

Polsky L, Von K, and Marina A (2017) Invited review: Effects of heat stress on dairy cattle welfare. Journal of dairy science 100:8645-8657.

Ravagnolo O, and Misztal I (2002) Effect of heat stress on nonreturn rate in Holsteins: fixed-model analyses. Journal of dairy science 85:3101-3106.

Sejian V, Maurya VP, and Naqvi SMK (2010) Adaptability and growth of Malpura ewes subjected to thermal and nutritional stress. Tropical Animal Health and Production 42:1763-1770

Tesfa A, Kumar D, Abegaz S, and Mekuriaw G (2017) Conservation and improvement strategy for Fogera cattle: A lesson for Ethiopia ingenious cattle breed resource. Advances in Agriculture 2017.

Tesfa A, Kumar D, Abegaz S, Mekuriaw G, Bimerew T, Kebede A, Bitew A Ferede $Y$, Mazengia $H$, and Tilahun M (2016a) Growth and reproductive performance of Fogera cattle breed at Andassa Livestock Research Center. Development 28:1.

Tesfa A, Kumar D, Abegaz S, Mekuriaw G, Bimerew T, Kebede A, Bitew A, 
Ferede Y, Mazengia H, and Tilahun MJD (2016b) Growth and reproductive performance of Fogera cattle breed at Andassa Livestock Research Center. $28,1$.

Ugurlu, M, Teke B, Akdag F, and Arslan S (2014) Effect of the temperaturehumidity index, cold stress index and dry period length on birth weight of Jersey's calf. Bulgarian Journal of Agricultural Science 20:1227-1232.

Veerasamy S, John G, Lance B, and Cadaba P (2015) Climate Change Impact on Livestock: Adaptation and Mitigation Springer India.

Wang J, Li J, Wang F, Xiao J, Wang Y, Yang H, Li S, and Cao Z (2020) Heat stress on calves and heifers: a review. Journal of Animal Science and Biotechnology 11:1-8.

Weaver D, and Meijerhof R (1991) The effect of different levels of relative humidity and air movement on litter conditions, ammonia levels, growth, and carcass quality for broiler chickens. Poultry Science 70:746-755.

Wolfenson D, Flamenbaum I, and Berman A (1988) Dry period heat stress relief effects on prepartum progesterone, calf birth weight, and milk production. Journal of Dairy Science 71:809-818.
Yaylak E, Orhan H, and Daşkaya A (2015) Some environmental factors affecting birth weight, weaning weight, and daily live weight gain of Holstein's calves. Turkish Journal of Agriculture-Food Science and Technology 3:617-622.

Zeleke B, Kebede K, and Banerjee A (2016a) Estimation of Genetic Parameters for Growth Traits of Fogera and Holstein Friesian Crossbred Cattle at Metekel Ranch, Amhara Region, Ethiopia.

Zeleke B, Kebede K, and Kumar B (2016b) Estimation of genetic parameters for reproductive traits of Fogera and Holstein Friesian crossbred cattle at Metekel Ranch, Amhara region, Ethiopia. Online J Anim Feed Res 6:90-95.

Zeleke T, Beyene F, Deressa T, Yousuf J, and Kebede T (2021) Vulnerability of Smallholder Farmers to Climate change-induced Shocks in East Hararghe Zone, Ethiopia. Sustainability 13:2162.

Zewdu W, Thombre BM, and Bainwad DV (2014) Effect of macroclimatic factors on milk production and reproductive efficiency of Holstein Friesian $\times$ Deoni crossbred cows Journal of Cell and Animal Biology 8:51-60. 